\title{
The effect of chronic oral vitamin D supplementation on adiposity and insulin secretion in hypothalamic obese rats
}

\author{
Zoé M. Guareschi ${ }^{1,2 *}$, Ana C. Valcanaia ${ }^{1,2}$, Vanessa M. Ceglarek ${ }^{1,2}$, Pamela Hotz ${ }^{1}$, Bruna K. Amaral ${ }^{1}$, \\ Domwesley W. de Souza ${ }^{1}$, Thainan A. de Souza ${ }^{1,2}$, Tarlliza Nardelli ${ }^{1}$, Thiago R. Ferreira ${ }^{3}$, Nayara C. Leite ${ }^{3}$, \\ Camila Lubackzeuski ${ }^{3}$, Henriette R. de O. Emilio ${ }^{4}$ and Sabrina Grassiolli ${ }^{1,2}$ \\ ${ }^{1}$ Biologics Science and Health Center, Laboratory of Endocrine and Metabolic Physiology, \\ University of West Parana (UNIOESTE), Cascavel, PR, Brazil \\ ${ }^{2}$ Postgraduate Program in Biosciences and Health, Laboratory of Endocrine and Metabolic Physiology, \\ University of West Parana (UNIOESTE), Cascavel, PR, Brazil \\ ${ }^{3}$ Department of Structural and Functional Biology, Institute of Biology, University of Campinas, Campinas, SP, Brazil \\ ${ }^{4}$ Department of General Biology, Sector of Biological and Health Sciences, Ponta Grossa State University (UEPG), \\ Ponta Grossa, PR, Brazil \\ (Submitted 12 September 2018 - Final revision received 26 February 2019 - Accepted 11 March 2019 - First published online 13 June 2019)
}

\section{Abstract}

Reduced plasma vitamin D (VD) levels may contribute to excessive white adipose tissue, insulin resistance (IR) and dyslipidaemia. We evaluated the effect of chronic oral VD supplementation on adiposity and insulin secretion in monosodium glutamate (MSG)-treated rats. During their first $5 \mathrm{~d}$ of life, male neonate rats received subcutaneous injections of MSG ( $4 \mathrm{~g} / \mathrm{kg}$ ), while the control (CON) group received saline solution. After weaning, groups were randomly distributed into VD supplemented ( $12 \mu \mathrm{g} / \mathrm{kg}$; three times/week) and non-supplemented (NS) rats, forming four experimental groups ( $n 15$ rats/group): CON-NS, CON-VD, MSG-NS and MSG-VD. At $76 \mathrm{~d}$ of life, rats were submitted to an oral glucose tolerance test (OGTT; $2 \mathrm{~g} / \mathrm{kg}$ ), and at $86 \mathrm{~d}$, obesity, IR and plasma metabolic parameters were evaluated. Pancreatic islets were isolated for glucoseinduced insulin secretion (GIIS), cholinergic insulinotropic response and muscarinic 3 receptor (M3R), protein kinase C (PKC) and protein kinase A (PKA) expressions. Pancreas was submitted to histological analyses. VD supplementation decreased hyperinsulinaemia (86 \%), hypertriacylglycerolaemia ( $50 \%$ ) and restored insulin sensibility (89\%) in MSG-VD rats, without modifying adiposity, OGTT or GIIS, compared with the MSG-NS group. The cholinergic action was reduced (57\%) in islets from MSG-VD rats, without any change in M3R, PKA or PKC expression. In conclusion, chronic oral VD supplementation of MSG-obese rats was able to prevent hyperinsulinaemia and IR, improving triacylglycerolaemia without modifying adiposity. A reduced cholinergic pancreatic effect, in response to VD, could be involved in the normalisation of plasma insulin levels, an event that appears to be independent of M3R and its downstream pathways.

Key words: Obesity: Insulin: Islets: Vitamin D

Vitamin D (VD) is an active circulating pre-hormone with a well-defined role in $\mathrm{Ca}$ and $\mathrm{P}$ homeostasis ${ }^{(1)}$. While VD can be obtained from dietary sources ${ }^{(2)}$, subcutaneous skin production, via the action of UVB irradiation, is the principal route of VD synthesis in the human body ${ }^{(3)}$. The biological activity of VD is dependent on the consecutive action of two hydroxylases present in the liver (25-hydroxylase) and in the kidney (1- $\alpha$-hydroxylase), generating 1,25 -dihydroxy-VD $\left(1,25(\mathrm{OH})_{2} \mathrm{D}\right)^{(3,4)}$. The activation of VD receptors (VDR) by VD mediates the pleiotropic functions of these hormone in several tissues ${ }^{(3-5)}$.

Several common conditions, such as low sunshine exposure, malabsorption and ageing, are related to VD deficiency ${ }^{(6)}$. However, in recent decades the associations between excessive white adipose tissue (WAT) content and VD deficiency have been observed in some studies ${ }^{(1,3)}$, a condition that could favour the metabolic abnormalities present in obesity ${ }^{(7,8)}$. In this regard,

Abbreviations: 1,25(OH) 2 D, 1,25-dihydroxy-vitamin D; 25(OH)D, 25-hydroxy-vitamin D; BW, body weight; CON, control; GIIS, glucose-induced insulin secretion; HOMA-IR, homeostatic model assessment of insulin resistance; IR, insulin resistance; M3R, muscarinic 3 receptor; MSG, monosodium glutamate; NS, nonsupplemented; OGTT, oral glucose tolerance test; PKA, protein kinase A; PKC, protein kinase C; VD, vitamin D; VDR, vitamin D receptor; WAT, white adipose tissue.

* Corresponding author: Zoé Maria Guareschi, email nutrizoemaria@gmail.com 
obesity is an important component of the metabolic syndrome, defined as the association of insulin resistance (IR), glucose intolerance $^{(9)}$, dyslipidaemia, hypertension and excessive WAT visceral content ${ }^{(10)}$. Thus, obesity and the metabolic syndrome are conditions intimately related to the development of type 2 diabetes mellitus and CVD worldwide ${ }^{(7,9-11)}$. It has been demonstrated that VD supplementation could improve glucose tolerance, pancreatic $\beta$-cell function and insulin sensitivity ${ }^{(6-8,12,13)}$, although these actions have not been confirmed by all authors ${ }^{(14-17)}$.

VD has direct effects on the endocrine pancreas ${ }^{(12)}$. In the pancreatic $\beta$-cell, the presence of VDR and the expression of $1 \alpha$-hydroxylase enzyme is well established ${ }^{(5,14,18,19)}$. Rodents with VD depletion present impaired insulin secretion ${ }^{(8,13)}$. Moreover, glucose-induced insulin secretion (GIIS) is diminished in islets from VDR-mutant mice ${ }^{(5,18)}$. The stimulus of VDR on pancreatic $\beta$-cells appears to alter $\mathrm{Ca}^{2+}$ flux and modulates anti-inflammatory and anti-apoptotic pathways in the pancreas ${ }^{(20)}$. Similar effects were also found in a mouse insulinoma cell line (MIN6) ${ }^{(20)}$. In addition, the GIIS in the pancreatic $\beta$-cell is substantially modulated by acetylcholine (Ach), released from the vagus nerve, a response mediated by the muscarinic 2 receptor (M3R) and its downstream pathways, such as protein kinase $\mathrm{C}$ (PKC) and protein kinase A (PKA) ${ }^{(21,22)}$. Interestingly, islets from diabetics rats treated with VD presented a re-establishment of their cholinergic response and increased M3R expression ${ }^{(23)}$. Neonatal treatment of rodents with monosodium glutamate (MSG) provokes hypothalamic lesions, resulting in the development of obesity in adulthood ${ }^{(24)}$. The MSG-treated rats reproduces the same characteristics of the metabolic syndrome found in obese humans ${ }^{(24-26)}$. Moreover, isolated pancreatic islets from MSG-treated rats showed changes in GIIS and reduced cholinergic insulinotropic responsiveness ${ }^{(27,28)}$. In the present study, we evaluated whether chronic VD supplementation modifies the metabolic abnormalities induced by MSG treatment, particularly investigating their effects on GIIS and cholinergic responsiveness in isolated pancreatic islets.

\section{Experimental methods}

\section{Ethical aspects}

All experimental procedures were conducted with male Wistar rats, where the number of animals used in each protocol was determined following previous similar studies ${ }^{(28,29)}$. During lactation and growth, rats were maintained in adequate conditions, according to the guidelines of the National Council for Control of Animal Experiments, following international norms for animal care and maintenance, as recommended by the Arrive Guidelines $^{(30)}$. The rats were kept in plastic cages ( $n$ 3-4 rats/ cage) with a stainless steel cover and housed in a controlled environment, with a 12-h light cycle, constant temperature $\left(21 \pm 2^{\circ} \mathrm{C}\right)$ and free access to food and water ${ }^{(31)}$. All experimental protocols were previously approved by the Ethics Committee on Animals Use (CEUA/15 November 2015) of the Western Parana State University (UNIOESTE).

\section{Hypothalamic obesity induction}

At birth, the size of the offspring was adjusted to six male pups per dam to ensure adequate nutritional lactation ${ }^{(31,32)}$. From the second to the sixth day of life, male Wistar ( $n$ 30) rats received daily subcutaneous injections of MSG in a dose of $4 \mathrm{~g} / \mathrm{kg}$ body weight $(\mathrm{BW})^{(28,29)}$. During the same period, the control (CON) rats $(n 30)$ received subcutaneous injection of $\mathrm{NaCl}$ solution $(1.25 \mathrm{~g} / \mathrm{kg} \mathrm{BW})$. At $30 \mathrm{~d}$ of life, the MSG and CON rats were weaned and randomly assigned to VD-supplemented or nonsupplemented (NS) groups, according to the protocol described in the next section. Thus, considering the obesity treatment and VD supplementation, four experimental groups were formed ( $n 15$ rats/group), as shown in Fig. 1: CON-NS: control non-supplemented; CON-VD: control VD-supplemented; MSG-NS: MSG non-supplemented; MSG-VD: MSG VD-supplemented.

\section{Vitamin D supplementation}

From 30 to $85 \mathrm{~d}$ of life, the VD-supplemented groups received SupraD $^{\circledR}$ at a dose of $12 \mu \mathrm{g} / \mathrm{kg}^{(32,33)}$ of BW dissolved in corn oil (vehicle). The VD dose was administered orally between 9.00 and 11.00 hours, three times per week, by gavage. To simulate the stress of oral supplementation, the NS groups also received the same volume of vehicle but without VD, for the same period and at the same frequency as for the VD-supplemented groups.

\section{Body weight, growth and food intake}

From 30 to $85 \mathrm{~d}$ of life, BW and food intake were monitored three times a week. For this, rats received a tail mark and had their BW individually registered in grams. To calculate food intake, the difference between the total of food offered and the amount of food remaining from the previous $48 \mathrm{~h}$ was obtained and divided by the number of rats per cage by individual $\mathrm{BW}^{(34,35)}$. Thus, food intake was expressed in $\mathrm{g} / \mathrm{g}$ of BW. The standard chow diet (BIOBASE, SC, Brazil) used in the present study followed the recommendations of the American Institute of Nutrition (AIN)-93 $3^{(36)}$ and contained $1.1 \% \mathrm{Ca} ; 0.8 \% \mathrm{P}$ and $0 \cdot 1 \mu \mathrm{g} / \mathrm{g}$ VD. Food and tap water were offered ad libitum. The data obtained from food intake and BW were used to elaborate the curves of food and BW evolution, and the respective AUC was calculated for both parameters.

\section{Oral glucose tolerance test}

At $76 \mathrm{~d}$ of life and after $12 \mathrm{~h}$ of fasting, 6-9 rats from each experimental group were submitted to glucose load ( $2 \mathrm{~g} / \mathrm{kg} \mathrm{BW}$ ) by oral gavage. Blood sample was collected by puncture of the tail vein at time 0 (before glucose load) and at times 15, 30, 60 and 120 min after glucose loading, and plasma glucose levels were measured using a glucometer (Accu-Chek Active ${ }^{\circledR}$ ). The glucose concentration during an oral glucose tolerance test (OGTT) was used to calculate the AUC.

\section{Biometric parameters and white adipose tissue content}

At $86 \mathrm{~d}$ of life and after $12 \mathrm{~h}$ of fasting, the animals were euthanised by decapitation after previous desensitisation with $\mathrm{CO}_{2}$. Peripheral blood was immediately collected in heparinised tubes for the measurement of plasma biochemical parameters, as described in the next section. In order to analyse the different fat depots, perirenal (visceral) and inguinal (subcutaneous) depots of WAT were removed and weighed. BW (g) and naso-anal length $(\mathrm{cm})$ were used to calculate the Lee index, using the formula, Lee index $={ }^{3} \sqrt{ } \mathrm{BW}(\mathrm{g}) /$ naso-anal length 
$(\mathrm{cm})$, as previously established by Bernardis \& Patterson ${ }^{(37)}$ and Rogers \& $\mathrm{Webb}^{(38)}$

\section{Blood biochemistry parameters and insulin resistance}

The peripheral blood collected was centrifuged $(3000 \mathrm{rpm} / \mathrm{min}$; $15 \mathrm{~min}$ ) and the plasma obtained was used to measure glucose, TAG and total cholesterol using colorimetric enzymatic kits (Lab Test, BR; GPO-Trinder, BR, respectively) according to the manufacturer's instructions. The plasma insulin level was evaluated by radioimmunoassay. Plasma glucose $(\mathrm{mmol} / \mathrm{l})$ and insulin $(\mu \mathrm{U} / \mathrm{ml})$ levels were used to calculate the homeostatic model assessment of insulin resistance (HOMA-IR) using the formula: HOMA-IR $=$ insulin $(\mu \mathrm{U} / \mathrm{ml}) \times$ glucose $(\mathrm{mmol} / \mathrm{l}) / 22 \cdot 5$, as previously established by Matthews et al. ${ }^{(39)}$ This measurement has been validated for rodents ${ }^{(40)}$. Plasma $\mathrm{Ca}$ and $\mathrm{P}$ were measured by colorimetric methods. The reagent for the quantitative determination of inorganic $\mathrm{P}$ was used for the dosage of $\mathrm{P}$ in plasma using an automated Beckman Coulter AU5800 analyser (range $0.5-17.9 \mathrm{mg} / \mathrm{dl} ; 0 \cdot 16-5.8 \mathrm{mmol} / \mathrm{l})$. The HumaStar 600 analyser and Calcium Liquicolor Multipurpose (Hummann inVitro) reagent were used for $\mathrm{Ca}$ dosage in plasma. Moreover, the 25-hydroxy-VD (25(OH)D) level was evaluated by Chemiluminescent Microparticle Immunoassay using an automated Architect Abbott i1000SR, employing Abbott Architect $25(\mathrm{OH}) \mathrm{D}$ reagent (assay range $0 \cdot 0-160 \cdot 0 \mathrm{ng} / \mathrm{ml}(400 \cdot 0 \mathrm{nmol} / \mathrm{l})$ ). Importantly, all kits were developed for use in human plasma; but as free $\mathrm{Ca}$, free $\mathrm{P}$ and $25(\mathrm{OH}) \mathrm{D}$ are chemically identical across species, no species differences were anticipated.

\section{Pancreatic islet isolation and insulin secretion}

Groups of 5-6 rats per group were used for pancreatic islet isolation by the collagenase technique, according to a previous protocol established by Lacy \& Kostianovsky ${ }^{(41)}$, with modifications $^{(42)}$. Briefly, the common bile duct was localised and perfused with Hanks buffer solution (HBS), pH 7.4, and $0 \cdot 1 \%$ bovine serum albumin (BSA), containing collagenase type $\mathrm{V}$ ( $1 \mathrm{mg} / \mathrm{ml}$ ). The pancreas was then perfused by retrograde flux via the pancreatic duct and immediately excised and then digested at $37^{\circ} \mathrm{C}$. The islets were manually collected, washed in HBS and transferred to wells in culture plates containing $1 \mathrm{ml}$ of Krebs buffer solutions, $\mathrm{pH} 7 \cdot 4$, and $0 \cdot 1 \%$ of BSA in the presence of $5.6 \mathrm{~mm}$ glucose. During the pre-incubation phase, the isolated pancreatic islets (four islets/well) were transferred to a culture chamber $\left(95 \% \mathrm{CO}_{2}\right)$ at $37^{\circ} \mathrm{C}$ for $60 \mathrm{~min}$. After pre-incubation, the medium was changed and the isolated pancreatic islets received $1 \mathrm{ml}$ of Krebs solutions containing 5.6 or $8.3 \mathrm{~mm}$ glucose to evaluate GIIS. Other islet groups received $1 \mathrm{ml}$ of Krebs solution containing $8.3 \mathrm{~mm}$ glucose in the presence of the cholinergic agonist, carbachol $(10 \mu \mathrm{M})$. Aliquots for all islet experiments were used to measure insulin by radioimmunoassay. GIIS was expressed as $\mathrm{ng} / \mathrm{ml}$ per four islets. The insulinotropic effect of carbachol was expressed as a percentage, considering the effect of $8.3 \mathrm{~mm}$ glucose as $100 \%$.

\section{Histological analysis of pancreas}

Firstly 4-6 pancreas per group were removed, dissected, weighed and placed in histological cassettes, before being immediately transferred to the fixative solution ALFAC (alcohol $70 \%$, formalin 37-40\% and glacial acetic acid) for $24 \mathrm{~h}$. Dehydration was performed by passing the samples through ethanol solutions of increasing graduation (70, 80, 90 and $100 \%)$. The samples were then diaphanised in xylol and were finally embedded in Paraplast (Surgipath Paraplast; Leica Biosystems). The tissues were sectioned at $5 \mu \mathrm{m}$ on a Reichert Jung rotary microtome (Leica RM 2025 Microsystems Inc.), and haematoxylin and eosin were used for staining. Microscopic analysis of stained preparations was carried out using an Olympus BX51 and digital photographs were taken with a digital 36-bit still colour camera, $1280 \times 1024$ pixels, with a DP71 Controller (Olympus). Image $\mathrm{J}^{\circledR} 1.42 \mathrm{q}$ software, available from the National Institute of Mental Health site (http://rsb.info.nih.gov/ij, accessed 15 June 2017), was employed for the analyses of numbers and areas of pancreatic islets. Approximately 3-5 microscopic fields per section and three sections per animal (six rats per group) were analysed. The mean of the pancreatic islets area was expressed as a percentage of the values observed in the CON-NS group (regarded as $100 \%$ ).

\section{Western blotting}

Islets from 4-6 rats for each group were solubilised in buffer containing $100 \mathrm{~mm}$ Tris, $\mathrm{pH}$ 7·5, $10 \mathrm{mmol} / \mathrm{l}$ sodium pyrophosphate, $100 \mathrm{~mm}$ sodium fluoride, $10 \mathrm{mmol} / \mathrm{l}$ EDTA, $10 \mathrm{~mm}$ sodium vanadate, 2 mм phenylmethylsulfonyl fluoride and $2 \%$ Triton X-100, final $\mathrm{pH} 8.08$. The protein concentration in the supernatants was assayed using the Bradford assay ${ }^{(43)}$. For sodium dodecyl sulphate-polyacrylamide gel electrophoresis and Western blot analysis, samples were treated with Laemmli buffer. After heating to $95^{\circ} \mathrm{C}$ for $5 \mathrm{~min}$, the proteins were separated by electrophoresis (30 $\mathrm{mg} /$ lane, $10 \% \mathrm{gel})$ and transferred to nitrocellulose membranes. The membranes were blocked overnight at $4^{\circ} \mathrm{C}$ in Tris-buffered saline containing $5 \%$ skimmed milk. Subsequently, the membranes were incubated with a polyclonal antibody against Ach-M3R (1:200, catalogue M6598; Sigma); for evaluating PKA $\alpha$ expression, the membranes were incubated with a polyclonal antibody against PKA $\alpha$ (1:200, catalogue SC903; Sigma) and an anti-PKC antibody (Pkc $\alpha$, sc-8393; SCBT). After washing, the membranes were incubated for $2 \mathrm{~h}$ with a secondary antibody (1:10 000; Invitrogen), followed by exposure to ImageQuant LAS 4000 Mini (GE Healthcare BioSciences) to detect the chemiluminescence of nitrocellulose membranes. After assaying the target protein, Western blotting was repeated using an $\alpha$-tubulin (1:1000, catalogue T6199; Sigma) antibody, as an internal control. Band intensities were quantified by optical densitometry using Image $J^{\circledR}$ software. Data are expressed as normalisation of Ach-M3R, PKA $\alpha$ and $\operatorname{PKC} \alpha: \alpha$-tubulin ratio.

\section{Statistical analysis}

Data are presented as means with their standard errors and analysed by two-way ANOVA. When $F$ values were significantly different $(P<0.05)$, the Tukey post-test was applied to evaluate the difference between groups CON-NS, CON-VD, MSG-NS, MSG-VD. The statistical analyses were conducted using Prism for Macintosh, version 5.0 (GraphPad Software). 
Table 1. Effects of chronic supplementation with vitamin D (VD) on biometric parameters* (Mean values with their standard errors; $n 10-15$ rats per group)

\begin{tabular}{|c|c|c|c|c|c|c|c|c|c|c|c|}
\hline & \multicolumn{2}{|c|}{ CON-NS } & \multicolumn{2}{|c|}{ CON-VD } & \multicolumn{2}{|c|}{ MSG-NS } & \multicolumn{2}{|c|}{ MSG-VD } & \multirow[b]{2}{*}{ MSG $P$} & \multirow[b]{2}{*}{ VD $P$} & \multirow{2}{*}{$\begin{array}{c}\text { Interaction } \\
P\end{array}$} \\
\hline & Mean & SEM & Mean & SEM & Mean & SEM & Mean & SEM & & & \\
\hline Body weight (g) & $351 \cdot 62^{c, d}$ & 8.04 & $363.92^{\mathrm{c}, \mathrm{d}}$ & $6 \cdot 76$ & $268 \cdot 54^{a, b}$ & 11.35 & $248 \cdot 07^{a, b}$ & 6.00 & $<0.0001$ & 0.615 & 0.048 \\
\hline $\begin{array}{l}\text { Naso-anal } \\
\text { length }(\mathrm{cm})\end{array}$ & $22 \cdot 40^{c, d}$ & 0.19 & $22 \cdot 78^{\mathrm{c}, \mathrm{d}}$ & 0.13 & $19 \cdot 47^{a, b}$ & 0.26 & $19 \cdot 79^{a, b}$ & 0.26 & $<0.0001$ & 0.106 & 0.871 \\
\hline Lee index & $312 \cdot 80$ & 4.41 & $315 \cdot 20$ & 3.03 & 333.30 & 9.53 & $322 \cdot 20$ & 8.47 & 0.044 & 0.517 & 0.312 \\
\hline $\begin{array}{l}\text { Inguinal fat } \\
(\mathrm{g} / 100 \mathrm{~g})\end{array}$ & $0 \cdot 18^{c, d}$ & 0.02 & $0 \cdot 16^{c, d}$ & 0.01 & $0 \cdot 62^{a, b}$ & 0.08 & $0.46^{a, b}$ & 0.05 & $<0.0001$ & 0.071 & 0.201 \\
\hline $\begin{array}{c}\text { Perirenal fat } \\
(\mathrm{g} / 100 \mathrm{~g})\end{array}$ & $0.22^{c, d}$ & 0.02 & 0.29 & 0.02 & $0.36^{\mathrm{a}}$ & 0.04 & $0.36^{a}$ & 0.03 & 0.0032 & 0.3522 & 0.3095 \\
\hline
\end{tabular}

CON-NS, control non-supplemented; CON-VD, control supplemented with VD; MSG-NS, monosodium glutamate non-supplemented; MSG-VD, MSG supplemented with VD. * Letters above numbers show statistical differences between groups by two-way ANOVA with Tukey post-test $(P<0.05)$. (a) CON-NS, (b) CON-VD, (c) MSG-NS and (d) MSG-VD.

Table 2. Effects of chronic supplementation with vitamin $D(V D)$ on biochemical plasma parameters and insulin resistance* (Mean values with their standard errors; $n 10-15$ rats per group)

\begin{tabular}{|c|c|c|c|c|c|c|c|c|c|c|c|}
\hline & \multicolumn{2}{|c|}{ CON-NS } & \multicolumn{2}{|c|}{ CON-VD } & \multicolumn{2}{|c|}{ MSG-NS } & \multicolumn{2}{|c|}{ MSG-VD } & \multirow[b]{2}{*}{ MSG $P$} & \multirow[b]{2}{*}{ VD $P$} & \multirow{2}{*}{$\begin{array}{c}\text { Interactior } \\
P\end{array}$} \\
\hline & Mean & SEM & Mean & SEM & Mean & SEM & Mean & SEM & & & \\
\hline Glycaemia $(\mathrm{mg} / \mathrm{dl}) \dagger$ & $105 \cdot 90^{c}$ & $9 \cdot 39$ & $107 \cdot 70^{c}$ & 9.08 & $153 \cdot 60^{\mathrm{a}, \mathrm{b}}$ & $14 \cdot 78$ & $128 \cdot 20^{a}$ & $10 \cdot 48$ & 0.0027 & 0.2792 & 0.2138 \\
\hline Insulinaemia (ng/ml) & $0.42^{c}$ & 0.09 & $1.22^{c}$ & 0.34 & $3.92^{a, b, d}$ & 0.93 & $0.55^{c}$ & 0.13 & 0.0020 & 0.0046 & 0.0007 \\
\hline TAG (mg/dl) $\dagger$ & $84.98^{c}$ & $8 \cdot 26$ & $69.98^{c}$ & 7.94 & $127 \cdot 60^{\mathrm{a}, \mathrm{b}, \mathrm{d}}$ & 11.97 & $63 \cdot 28^{c}$ & $8 \cdot 64$ & 0.0599 & 0.0001 & 0.0126 \\
\hline $\begin{array}{l}\text { Total cholesterol } \\
(\mathrm{mg} / \mathrm{dl}) \dagger\end{array}$ & $105 \cdot 60^{d}$ & 4.50 & $108 \cdot 80^{d}$ & $5 \cdot 19$ & $120 \cdot 30^{d}$ & $10 \cdot 50$ & $160 \cdot 70^{a, b, c}$ & $5 \cdot 12$ & $<0.0001$ & 0.0031 & 0.0106 \\
\hline HOMA-IR & $3 \cdot 12^{c}$ & 0.79 & $7 \cdot 63^{\mathrm{c}}$ & 2.03 & $49 \cdot 04^{a, b, d}$ & 14.52 & $5 \cdot 17^{\mathrm{c}}$ & 0.58 & 0.0349 & 0.0426 & 0.0102 \\
\hline $\mathrm{Ca}(\mathrm{mg} / \mathrm{dl}) \dagger$ & $9 \cdot 71^{d}$ & $0 \cdot 18$ & 9.54 & 0.21 & $10 \cdot 97$ & 0.67 & $11 \cdot 19^{a}$ & 0.49 & 0.0009 & 0.9427 & 0.6373 \\
\hline$P(\mathrm{mg} / \mathrm{dl}) \dagger$ & 7.43 & 0.13 & 7.46 & 0.19 & $7 \cdot 37$ & 0.16 & 7.50 & 0.13 & 0.9597 & 0.6468 & 0.7428 \\
\hline 25-OH-vitamin $\mathrm{D}(\mathrm{nmol} / \mathrm{l})$ & $33 \cdot 36^{b, d}$ & 0.70 & $40 \cdot 74^{\mathrm{a}, \mathrm{c}}$ & $2 \cdot 74$ & $33 \cdot 27^{\mathrm{b}, \mathrm{d}}$ & 1.33 & $45 \cdot 01^{\mathrm{a}, \mathrm{c}}$ & 1.83 & 0.1977 & $<0.0001$ & 0.1789 \\
\hline
\end{tabular}

CON-NS, control non-supplemented; CON-VD, control supplemented with VD; MSG-NS, monosodium glutamate non-supplemented; MSG-VD, MSG supplemented with VD; HOMA-IR, homeostatic model assessment of insulin resistance.

* Letters above numbers show statistical differences between groups by two-way ANOVA with Tukey post-test $(P<0.05)$. (a) CON-NS, (b) CON-VD, (c) MSG-NS and (d) MSG-VD.

$\dagger$ To convert glycaemia in $\mathrm{mg} / \mathrm{dl}$ to $\mathrm{mmol} / \mathrm{l}$, multiply by 0.0555 . To convert TAG in $\mathrm{mg} / \mathrm{dl}$ to $\mathrm{mmol} / \mathrm{l}$, multiply by 0.0113 . To convert cholesterol in $\mathrm{mg} / \mathrm{dl}$ to $\mathrm{mmol} / \mathrm{l}$, multiply by 0.0259 .

To convert $\mathrm{Ca}$ in $\mathrm{mg} / \mathrm{dl}$ to $\mathrm{mmol} / \mathrm{l}$, multiply by 0.25 . To convert $\mathrm{P}$ in $\mathrm{mg} / \mathrm{dl}$ to $\mathrm{mmol} / \mathrm{l}$, multiply by 0.323 .

\section{Results}

The effects of chronic supplementation with VD on the biometric parameters of rats are shown in Table 1. At $86 \mathrm{~d}$ of life, BW was affected by MSG treatment $\left(F_{1,50}=151 \cdot 1 ; P<0 \cdot 0001\right)$ and also by the interaction of VD supplementation and MSG treatment $\left(F_{1,50}=4 \cdot 101 ; P=0 \cdot 048\right)$. Naso-anal length was affected only by neonatal treatment with MSG $\left(F_{1,50}=151 \cdot 1 ; \quad P<0.0001\right.$; $\left.F_{1,80}=193.0 ; P<0.0001\right)$ and no influence of VD supplementation was observed $\left(F_{1,50}=0.252 ; P=0 \cdot 6156 ; F_{1,80}=2 \cdot 664 ; P=0 \cdot 1066\right)$, where BW and naso-anal length were significantly lower in MSGNS and MSG-VD rats, in relation to the CON-NS and CON-VD groups $(P<0.05)$. Neither MSG treatment nor VD supplementation affected the Lee index. MSG treatment also modulated subcutaneous $\left(F_{1,54}=50.56 ; \quad P<0.0001\right)$ and visceral $\left(F_{1,58}=9.431\right.$; $P=0.0032)$ fat depots, where MSG-NS and MSG-VD rats presented higher fat accumulation compared with the CON groups $(P<0 \cdot 05)$.

Table 2 presents the effects of chronic VD supplementation on biochemical parameters in the plasma. MSG treatment $\left(F_{1,49}=9.985 ; P=0.0027\right)$ significantly increased plasma glucose levels in MSG-NS and MSG-VD rats, compared with the levels in the CON-NS group $(P<0.05)$. The plasma level of insulin was affected by the interaction of MSG treatment and VD supplementation $\left(F_{1,44}=20.41 ; P<0.0001\right)$, where MSG-NS rats presented higher plasma insulin levels compared with the CONNS and MSG-VD groups $(P<0 \cdot 05)$.

Plasma levels of TAG and total cholesterol were influenced by MSG treatment $\left(F_{1,33}=3.796 ; P=0.0599 ; F_{1,35}=23.51 ; P<0.0001\right)$ and VD supplementation $\left(F_{1,33}=18.35 ; P=0.0001 ; F_{1,35}=10 \cdot 07\right.$; $P=0.0031)$, as well as by the interaction between these factors $\left(F_{1,32}=5.797 ; P=0.220 ; F_{1,35}=7 \cdot 302 ; P=0.0106\right)$. MSG-NS rats demonstrated increased plasma TAG compared with the levels in the CON-NS, CON-VD and MSG-VD groups $(P<0 \cdot 05)$. In addition, plasma total cholesterol level was higher in MSG-VD rats in relation to other groups $(P<0 \cdot 05)$. Insulin sensibility was also influenced by MSG treatment $\left(F_{1,38}=0.4787 ; P=0.0349\right)$ and VD supplementation $\left(F_{1,38}=4.403 ; \quad P=0.0426\right)$, as well as by the interactions between these factors $\left(F_{1,38}=7 \cdot 305 ; P=0.0102\right)$. Thus, the HOMA-IR value was increased in MSG-NS animals, compared with the CON-NS, CON-VD and MSG-VD groups $(P<0.05)$. Moreover, VD supplementation had a significant effect $\left(F_{1,40}=3601 ; P<0.0001\right)$ on plasma $25(\mathrm{OH}) \mathrm{D}$ level. Thus, in CON-VD and MSG-VD rats, higher 25(OH)D levels were found, in relation to the respective NS animals $(P<0.05)$. MSG treatment exerted effects on Ca plasma levels $\left(F_{1,49}=12 \cdot 60 ; P=0.009\right)$, where the MSG-VD rats presented slightly greater Ca levels than 


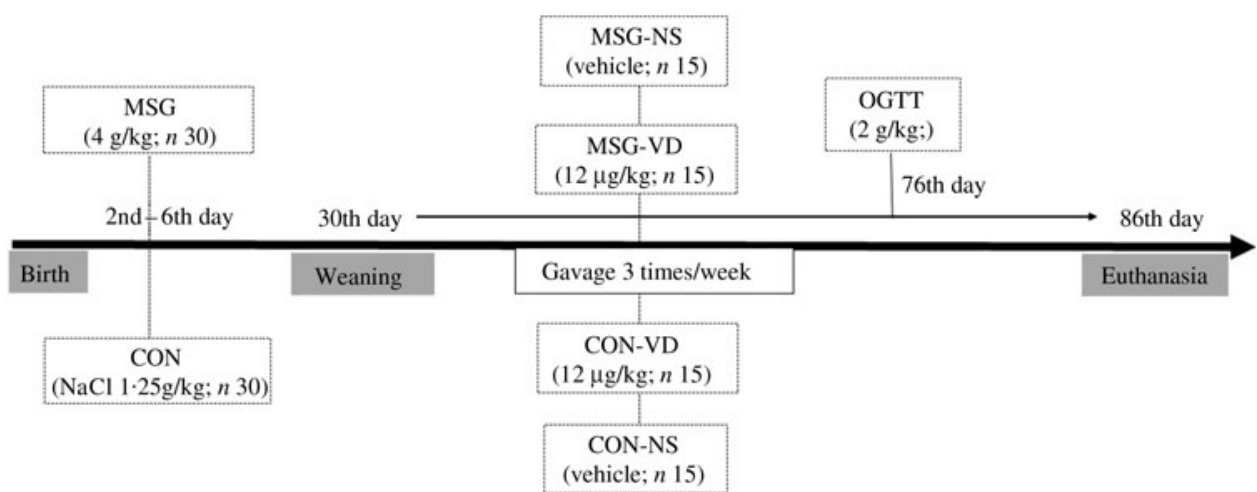

Fig. 1. Experimental design. MSG, monosodium glutamate; CON, control; CON-NS, control non-supplemented; CON-VD: control supplemented with vitamin D; MSG-NS, MSG non-supplemented; MSG-VD, MSG supplemented with vitamin D; OGTT, oral glucose tolerance test.

(A)

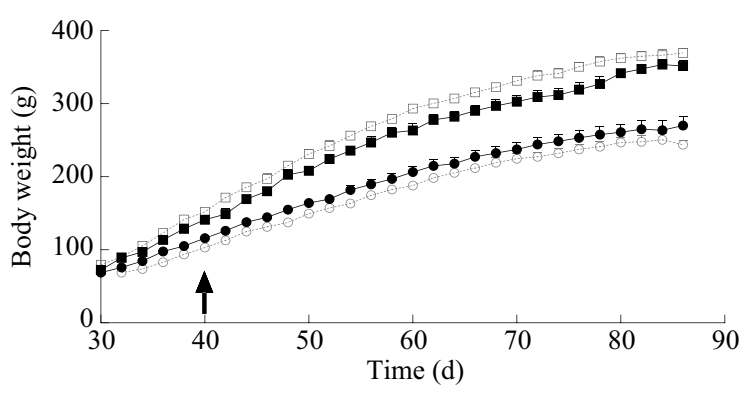

(C)

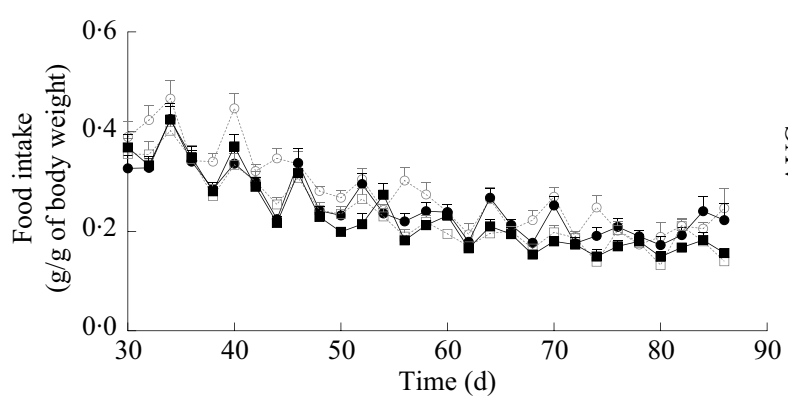

(B)

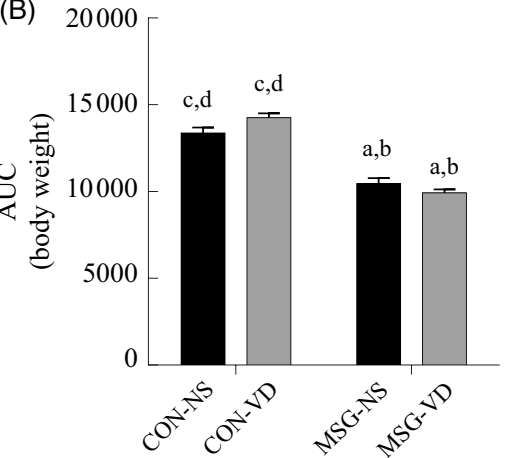

(D)

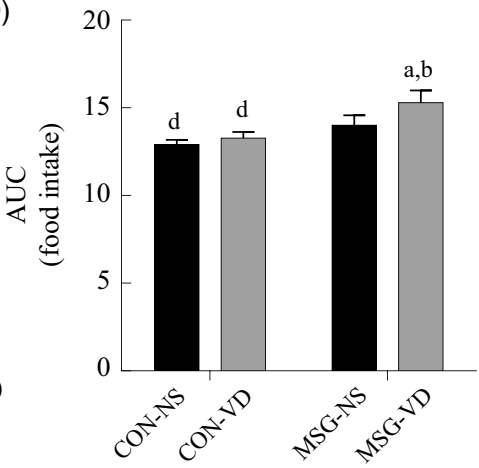

Fig. 2. Effect of neonatal treatment with monosodium glutamate (MSG) and vitamin D supplementation on body weight and food intake. Body weight (A) and food intake (C) were evaluated from 30 to $86 \mathrm{~d}$ and the respective AUC calculated (B and D). The arrow in (A) indicates the beginning of statistical difference $(P<0.05)$ between rats from the MSG and control groups. ---, Control non-supplemented (CON-NS); $\square-$-, control supplemented with vitamin D (CON-VD); ---, monosodium glutamate non-supplemented (MSG-NS); -O-, MSG supplemented with vitamin D (MSG-VD). Data are means ( $n$ 10-15 rats per group), with standard errors represented by vertical bars. ${ }^{\text {a,b,c,d }}$ Letters above bars show statistical differences between groups by two-way ANOVA with Tukey post-test $(P<0.05)$. (a) CON-NS, (b) CON-VD, (c) MSG-NS and (d) MSG-VD.

the CON-NS animals $(P<0.05)$. Neither MSG treatment nor VD supplementation affected plasma P levels

Fig. 2 presents the effects of chronic VD supplementation on growth (Fig. 2(A) and (B)) and food intake (Fig. 2(C) and (D)). Again, only an effect of MSG neonatal treatment was observed for both parameters $\left(F_{1,52}=167.5 ; \quad P<0.0001\right.$ and $F_{1,48}=9.403 ; P=0.0036$ ). From 40 to $86 \mathrm{~d}$ of age, MSG-NS and MSG-VD rats presented lower BW than CON groups, resulting in reduced BW AUC in the MSG animal groups, compared with the AUC of CON rats $(P<0.05)$. MSG treatment alone affected food intake; however, the association of MSG and VD supplementation did not alter the AUC for food intake.
At $76 \mathrm{~d}$ of age, rats were submitted to the OGTT (Fig. 3(A)). VD supplementation affected plasma glucose levels at $60 \mathrm{~min}$ $\left(F_{1,26}=9.159 ; \quad P=0.0055\right)$ and $120 \quad \min \quad\left(F_{1,26}=6.419\right.$; $P=0.0177)$ OGTT, where plasma glucose of CON-NS rats was lower than that of CON-VD rats at $60 \mathrm{~min}(P<0.05)$. Neither VD nor MSG treatment significantly influenced glucose levels at other times during OGTT. The AUC of OGTT demonstrated an effect of VD supplementation $\left(F_{1,26}=6.848 ; \quad P=0.0172\right)$ (Fig. 3(B)).

The effects of chronic VD supplementation on GIIS and the weight of endocrine pancreas are shown in Fig. 4(A) and (B) and the histological analysis is in Fig. 5(A)-(D). The weight of 
(A)

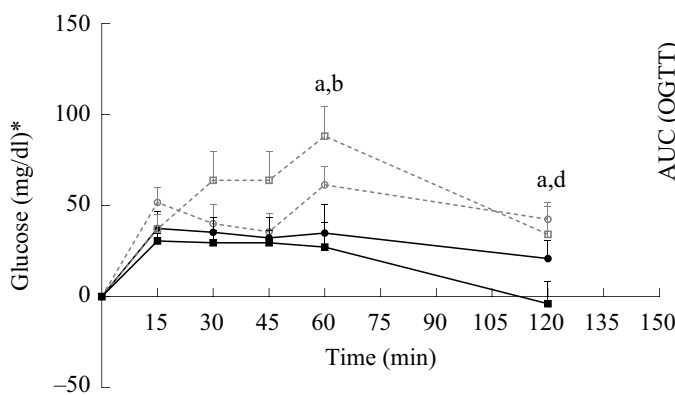

(B) 400

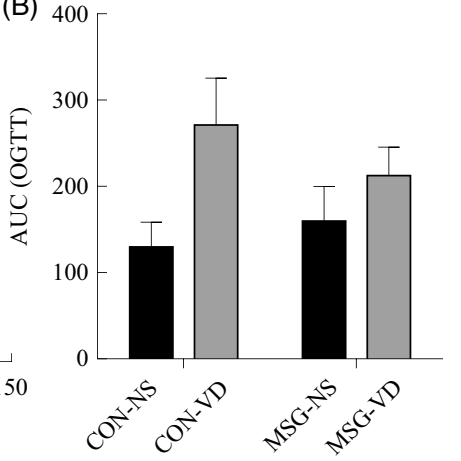

Fig. 3. Effect of neonatal treatment with monosodium glutamate (MSG) and chronic vitamin $D$ supplementation on oral glucose tolerance test (OGTT). Glycaemic curve after glucose loading (2 g/kg body weight) (A) and AUC (B). ---, Control non-supplemented (CON-NS); - $\square-$, control supplemented with vitamin D (CON-VD); ---, monosodium glutamate non-supplemented (MSG-NS); $-O-$, MSG supplemented with vitamin D (MSG-VD). Data are means ( $n 6-9$ rats per group), with standard errors represented by vertical bars. ${ }^{a, b, c, d}$ Letters above connecting lines and bars show statistical differences between groups by two-way ANOVA with Tukey post-test $(P<0.05)$. (a) CON-NS, (b) CON-VD, (c) MSG-NS and (d) MSG-VD. * To convert glucose in $\mathrm{mg} / \mathrm{dl}$ to $\mathrm{mmol} / \mathrm{l}$, multiply by 0.0555 .

(A)

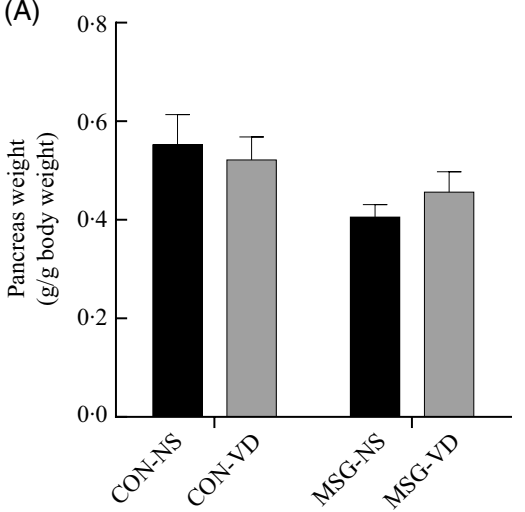

(B)

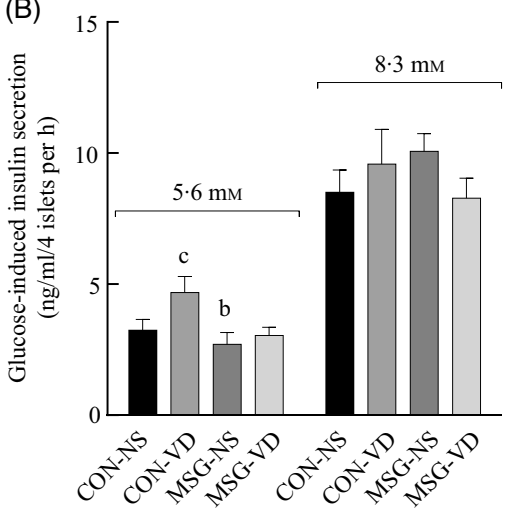

Fig. 4. Effect of neonatal treatment with monosodium glutamate (MSG) and chronic vitamin $D$ supplementation in endocrine pancreas. Weight of pancreas (A) and glucose-induced insulin secretion from isolated pancreatic islets at different glucose concentrations (5.6 and 8.3 mM of glucose) (B) are shown. CON-NS, control non-supplemented; CON-VD, control supplemented with vitamin D; MSG-NS, monosodium glutamate non-supplemented; MSG-VD, MSG supplemented with vitamin D. Data are means ( $n$ 5-6 rats per group), with standard errors represented by vertical bars. ${ }^{\text {a,b,c,d }}$ Letters above bars show statistical differences between groups by two-way ANOVA with Tukey post-test $(P<0.05)$. (a) CON-NS, (b) CON-VD, (c) MSG-NS and (d) MSG-VD.

pancreas was affected by MSG treatment $\left(F_{1,47}=5 \cdot 284\right.$; $P=0.0260)$; however, in post-test the mean weight of pancreas did not differ between groups. Light microscopic analysis of pancreatic islets showed a typical organisation, with an exocrine component presenting lobules, connective tissue septa and ducts. The endocrine component, represented by pancreatic islets, is embedded within the pancreatic exocrine tissue. The pancreatic islets presented circular, oval or elongated shapes with a thin connective sheath surrounding each islet. Although the islet size was affected by the interaction between VD and MSG treatments $\left(F_{1,19}=6 \cdot 201 ; P=0.0222\right)$, in the post-test the mean islet sizes of the groups was considered to be statistically similar.

The cholinergic agonist effect of carbachol $(10 \mu \mathrm{M})$ on GIIS is shown in Fig. 6(A). The insulinotropic action of carbachol was influenced by the interaction between MSG treatment and VD supplementation $\left(F_{1,59}=8.080 ; P=0.0061\right)$. Thus, in pancreatic islets from MSG-VD rats, a reduced cholinergic effect was observed in relation to islets from MSG-NS and CON-VD groups $(P<0.05)$. However, neither MSG treatment nor VD supplementation significantly affected M3R (Fig. 6(B)) or PKA (Fig. 6(D)) expression in isolated pancreatic islets. Nevertheless, an effect of the interactions between MSG treatment and VD supplementation was observed on PKC expression in isolated pancreatic islets $\left(F_{1,12}=6.303\right.$; $P=0.0274$ ) (Fig. 6(C)), where PKC protein expression was significantly higher in islets of rats from MSG-NS, compared with islets from the CON-NS group $(P<0 \cdot 05)$.

\section{Discussion}

The role of excessive WAT content is well recognised in the metabolic syndrome and diseases such as type 2 diabetes mellitus and $\mathrm{CVD}^{(7,10,11)}$, a condition that could be related to low levels of $\mathrm{VD}^{(1,3)}$. Several studies have evaluated the impact of VD supplementation on glucose and lipid homeostasis in rodents and humans ${ }^{(7,12,19)}$, although the data reported are contradictory ${ }^{(15-17)}$. In the present study, we explored the effects of chronic supplementation with VD on the hypothalamic obesity induced by MSG neonatal treatment. Confirming previously published data ${ }^{(24,25)}$, in our study, MSG-treated rats presented higher adiposity, lower BW and growth as well as normophagia in adulthood. Augmented 

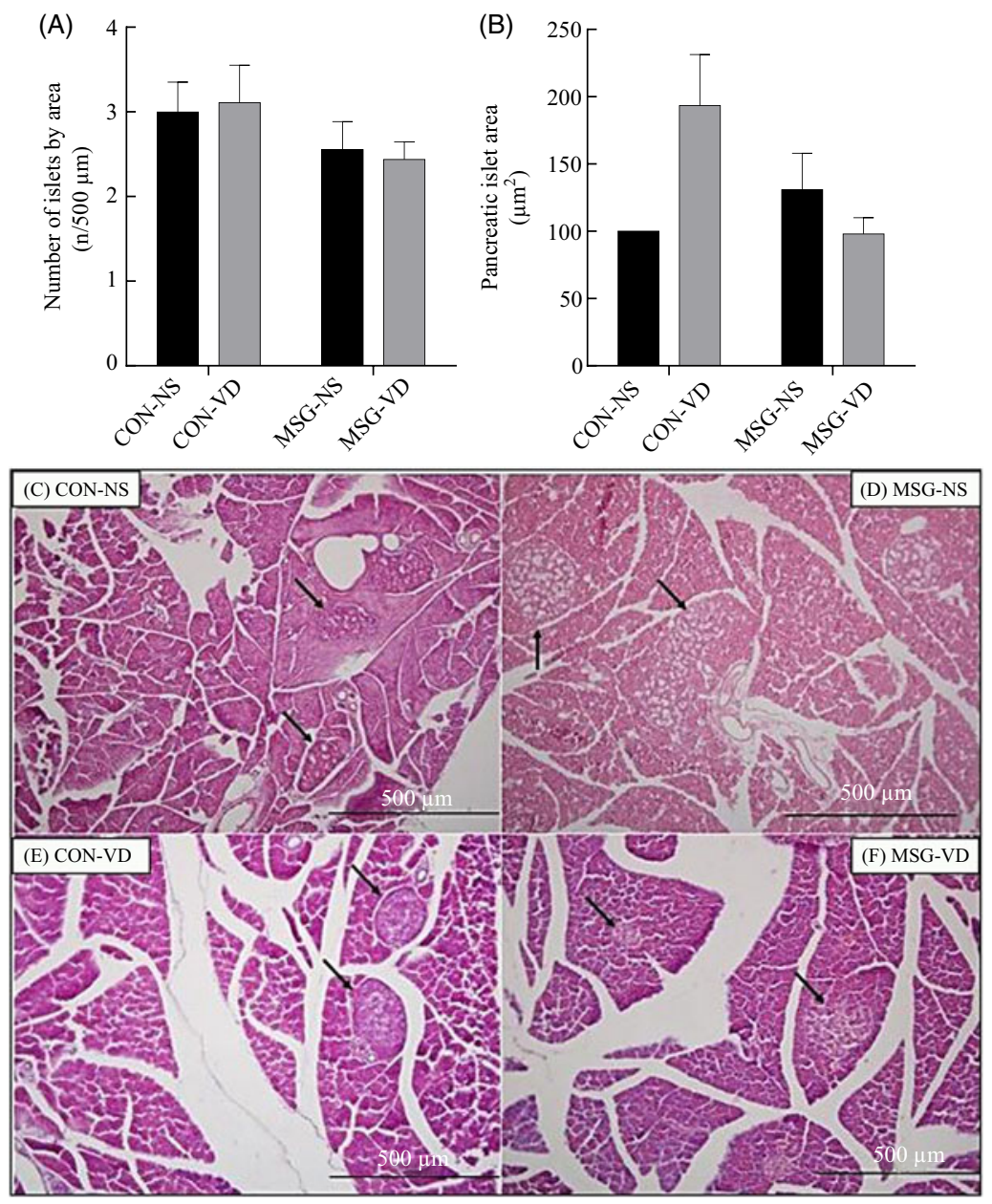

Fig. 5. Effect of neonatal treatment with monosodium glutamate (MSG) and chronic vitamin D supplementation on the endocrine pancreas. The number and mean size of pancreatic islets are represented in (A) and (B), respectively. Islet sizes were calculated by normalisation to the control non-supplemented (CON-NS) group. Representative photomicrography of pancreatic islets with haematoxylin and eosin stain, 10x magnification (C-F). Black arrows indicate pancreatic islets. CON-VD, control supplemented with vitamin D; MSG-NS, monosodium glutamate non-supplemented; MSG-VD, MSG supplemented with vitamin D. Data are means ( $n$ 4-6 rats per group), with standard errors represented by vertical bars, calculated through two-way ANOVA with Tukey post-test $(P<0.05)$.

lipogenesis activity ${ }^{(27)}$, hyperinsulinaemia ${ }^{(26-28)}$, lower growth hormone levels and neuronal hypothalamic rearrangements ${ }^{(24)}$ explain these profiles in the MSG obesity model. Herein, chronic VD supplementation $(12 \mu \mathrm{g} / \mathrm{kg}$ during $55 \mathrm{~d})$ did not affect visceral or subcutaneous WAT content in MSG-VD rats. In contrast, Marcotorchino et $a l{ }^{(3)}$ demonstrated that VD supplementation $(375 \mu \mathrm{g} / \mathrm{kg}$ of food for 10 weeks) reduced obesity in high-fat diet (HFD)-obese mice. The VDR is present in WAT, and its activation by VD might exert regulatory effects on adipogenesis, lipid metabolism and inflammatory processes ${ }^{(14,44)}$; however, inconsistent results regarding VD have been observed in several studies $^{(44-48)}$. In 3T3/L1 pre-adipocytes, for example, VD inhibited adipogenesis ${ }^{(46)}$, while enhanced lipid accumulation and increased expression of adipogenic marker genes were found in mesenchymal cells incubated with $\mathrm{VD}^{(47)}$. In mice without VDR expression $\left(\mathrm{VDR}^{-/}\right)$, reduced WAT was reported ${ }^{(18)}$. Recently, Jin et al. ${ }^{(49)}$ demonstrated that VD, when administered subcutaneously $(1 \mu \mathrm{g} / \mathrm{kg})$ in MSG-obese rats, reduced WAT content and adipocyte size. Differences in plasma VD levels could explain these discrepant results ${ }^{(50)}$. However, Jin et $a l .{ }^{(49)}$ did not measure VD, or its active metabolite, in plasma.
In the present study, we observed augmented levels of $1,25(\mathrm{OH})_{2} \mathrm{D}$ in supplemented rats, suggesting that oral administration was effective for elevating plasma VD levels.

In our study, we did not find any effect of chronic VD supplementation on BW gain or food intake in MSG-VD animals. Inconsistent effects of VD supplementation also were observed on these parameters. For example, VD supplementation in HFD-obese mice reduced food intake, weight gain and modulated the inflammatory response in the hippocampus and hypothalamus ${ }^{(51)}$. In contrast, in $\mathrm{VDR}^{-/-}$mice, reduced $\mathrm{BW}$ was observed, in association with normophagia ${ }^{(52)}$. The arcuate nucleus (ARC) has an important role in the neural control of food intake and energetic metabolism ${ }^{(26)}$. MSG-obese rats presented damage in the ARC neurons ${ }^{(24)}$, which would prevent a central hypothalamic action of VD.

Dyslipidaemia, hyperinsulinaemia and IR, which are metabolic characteristics of MSG-treated rats ${ }^{(24-26)}$, were reproduced in MSG-obese rats in the present study. VD modulates the expression of insulin receptors in peripheral tissues, such as skeletal muscle and WAT and also affects insulin sensitivity ${ }^{(53-57)}$. In our study, chronic VD supplementation in 
(A)

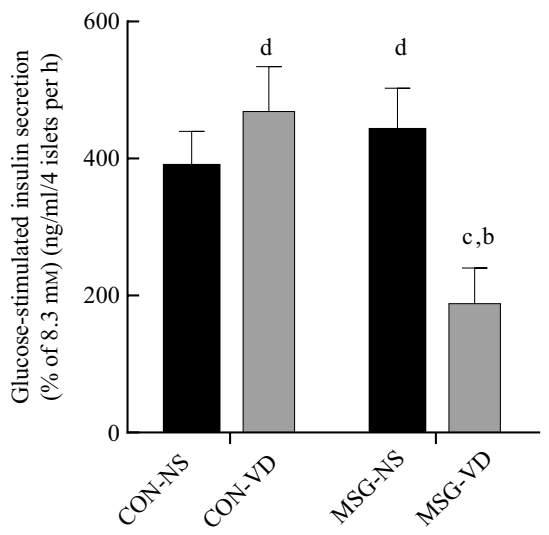

(C)
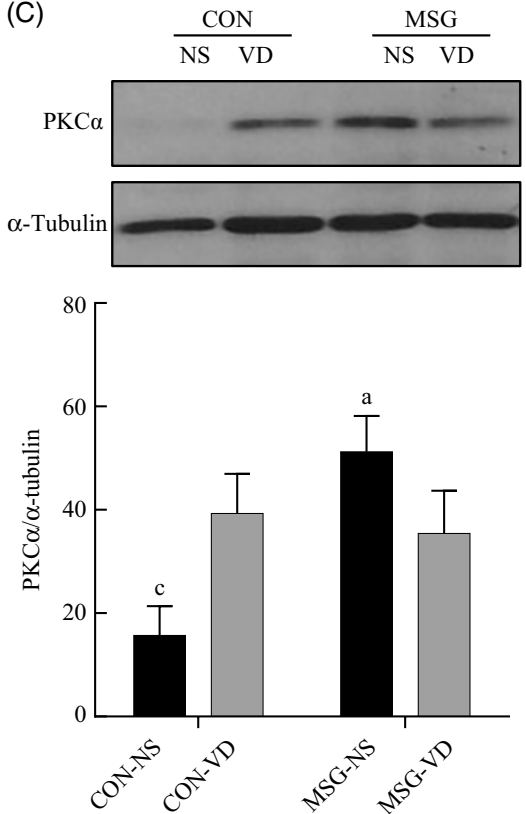

(B)

$$
\frac{\mathrm{CON}}{\mathrm{NS} \text { VD }} \quad \frac{\mathrm{MSG}}{\mathrm{NS} \text { VD }}
$$
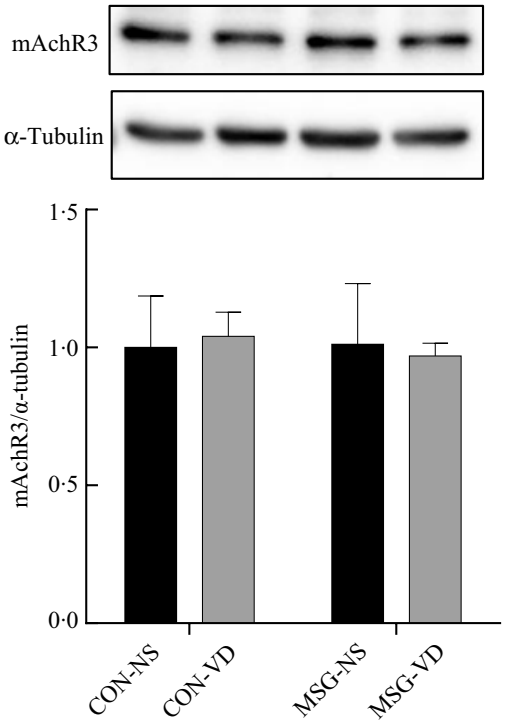

(D)
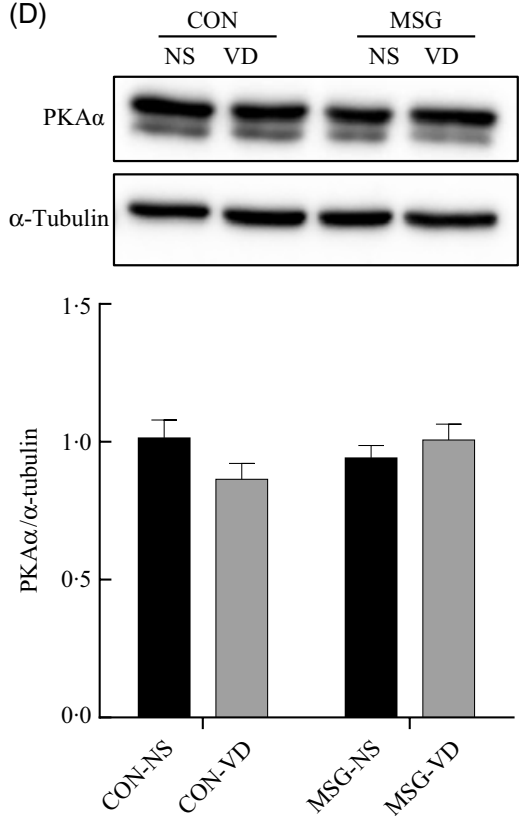

Fig. 6. Effect of neonatal chronic vitamin D supplementation on cholinergic response and protein expression in isolated pancreatic islets. Effect of neonatal chronic vitamin $\mathrm{D}$ supplementation on cholinergic response and protein expression in isolated pancreatic islets. Effect of carbachol $(\mathrm{CCh})(10 \mu \mathrm{m})$ on glucose-induced insulin secretion ( $8.3 \mathrm{~mm}$ ) is shown (A). mAchR3 (B), protein kinase $\mathrm{C} \alpha(\mathrm{PKC} \alpha)(\mathrm{C})$ and protein kinase $\mathrm{A} \alpha(\mathrm{PKA} \alpha)$ (D) protein expressions were obtained from isolated pancreatic islets. Results are expressed by the raw data obtained from the ratio of quantification of the protein of interest by the quantification of tubulin. CON-NS, control nonsupplemented; CON-VD, control supplemented with vitamin D; MSG-NS, monosodium glutamate non-supplemented; MSG-VD, MSG supplemented with vitamin D. Data are means ( $n$ 4-6 rats per group), with standard errors represented by vertical bars. ${ }^{\text {a,b,c,d }}$ Letters above bars show statistical differences between groups by twoway ANOVA with Tukey post-test $(P<0.05)$. (a) CON-NS, (b) CON-VD, (c) MSG-NS and (d) MSG-VD.

MSG-obese rats effectively normalised TAG and plasma insulin levels, and improved IR. Similar results were recently reported by Jin et al. ${ }^{(49)}$ using intraperitoneal $\mathrm{VD}$ administration in MSG-obese rats. VD supplementation also improved the metabolic profile in HFD-obese mice and in LDL receptor knockout mice ${ }^{(8)}$. The association between VD and lipid profiles, including TAG, was demonstrated in a longitudinal study by Jorde et al. ${ }^{(55)}$. In the present study, we noted that MSG-VD rats also presented high cholesterol levels, a response that could be related to differing effects of VD on the LDL and HDL-cholesterol subfractions, as already reported ${ }^{(55)}$. However, Jin et al. ${ }^{(49)}$ found no difference in LDL and HDL levels in MSG rats receiving intraperitoneal VD.

VD supplementation can improve hepatic lipid metabolism ${ }^{(50,56)}$. Here, using HOMA-IR, we observed that MSG-VD rats presented augmented insulin sensibility. As HOMA-IR appears to be a better indicator of hepatic $\mathrm{IR}^{(40)}$, it is possible that VD supplementation improved hepatic function contributing to better 
insulin responsiveness and, consequently, reduced TAG levels. Moreover, adequate VD status is also related to glucose homeostasis and $\beta$-cell function ${ }^{(58-62)}$. In the present study, oral VD supplementation did not alter either fasting plasma glucose or oral glucose tolerance. Similarly, glucose tolerance did not change in $\mathrm{VDR}^{-/(18)}$ and $\mathrm{VD}$-deficient mice ${ }^{(5)}$. In contrast, in type 2 diabetes mellitus patients with VD deficiency, the daily intake of a VD-fortified yogurt drink increased serum VD levels and improved glycaemic status ${ }^{(61)}$. Despite no changes in glucose tolerance, MSG-VD rats had reduced insulin plasmatic levels, suggesting an effect on the endocrine pancreas. In rats, VD deficiency impaired insulin release from the pancreas and reduced glucose tolerance, and these alterations were alleviated by VD supplementation $^{(13)}$. Moreover, in humans at a high risk of diabetes, cholecalciferol ( $50 \mu \mathrm{g}$ daily) supplementation for 16 weeks improved pancreatic $\beta$-cell function ${ }^{(53)}$. However, in the present study, neither GIIS nor islet number or size were significantly affected by VD supplementation in MSG-obese rats. Similarly, $\mathrm{VDR}^{-/}$mice maintained in normocalcaemia demonstrated no alterations in GIIS and islet morphology ${ }^{(5)}$. A recent study showed that MIN6 cultured in high glucose for a longer time presented reduced VDR expression ${ }^{(20)}$. In this study, the activation of VDR by VD did not significantly alter GIIS, either in MIN6 cells or in isolated pancreatic islets from $d b / d b$ mice, but increased insulin expression was observed ${ }^{(20)}$. In contrast, VD supplementation in type 1 diabetes mellitus (T1DM) rats increased insulin secretion and VDR expression in isolated pancreatic islets ${ }^{(5,33)}$. Ach is the main insulinotropic agent in the pancreatic $\beta$-cell; as such, changes in cholinergic responsiveness are involved in insulin hypersecretion in several models of obesity, including MSGobese rats ${ }^{(26-28)}$. The M3R subtype and its downstream pathways, particularly the PKC protein, are mainly responsible for the cholinergic effect in pancreatic $\beta$-cells ${ }^{(22)}$. Here, we found that islets from MSG-VD rats presented reductions in the cholinergic insulinotropic effect without changes in M3R and PKC protein expressions. In contrast, Kumar et al. ${ }^{(23)}$ demonstrated that VD supplementation in the T1DM model restored M3R in the endocrine pancreas. VD also appeared to regulate the expression of phosphodiesterase enzymes in pancreatic islets, which ${ }^{(18)}$ are important regulators of AMPc and, consequently, PKA activity ${ }^{(18)}$. However, in our study, we did not observe alterations in PKA expression in isolated pancreatic islets from MSG-VD supplemented rats. Interestingly, Ach, via the M2R subtype, exerted paradoxical inhibitory insulinotropic effects on islets from MSG-obese rats ${ }^{(22)}$. Thus, the effects of VD on other MR subtypes or pathways cannot be discarded. Taken together, these data suggest that the previous functional state of $\beta$-cell could determine the effects of VD on GIIS and cholinergic responses.

It is well established that the response to VD supplementation is dependent upon baseline VD concentrations ${ }^{(4)}$. In the present study, no alterations in $25(\mathrm{OH}) \mathrm{D}$ levels were found in MSGtreated rats. However, it is important to recognise that $1,25(\mathrm{OH})_{2} \mathrm{D}$ is the primary biologically active form of this hormone. As demonstrated by Parisi et al. ${ }^{(63)}$ an increase in renal glutamate levels could be involved in a decrease in renal $1 \alpha$ hydroxylase activity and, therefore, a decrease in $1,25(\mathrm{OH})_{2} \mathrm{D}$ levels. Moreover, in the present study, MSG-VD rats presented high $\mathrm{Ca}$ levels, without modifications in $\mathrm{P}$ concentration, a response also found in patients with chronic renal disease receiving $\mathrm{VD}^{(64)}$. Interestingly, MSG-treated rats might have renal dysfunctions $^{(65)}$, but the renal manipulations of $\mathrm{Ca}$ and $\mathrm{P}$ in this obese model are unknown. Additionally, MSG-obese rats might present high plasma cortisol and leptin levels, which could attenuate the actions of $\mathrm{VD}^{(50)}$.

In conclusion, our results indicate that chronic VD supplementation in MSG-obese rats reduced hypertriacylglycerolaemia, corrected hyperinsulinaemia and improved insulin sensibility without changing WAT content or GIIS from isolated pancreatic islets. However, the reduced insulinotropic cholinergic effect found in the pancreatic islets of MSG-VD rats may contribute to lower plasma insulin levels, an effect that is not directly related to changes in M3R expression or its downstream pathways.

\section{Acknowledgements}

This study forms part of the MSc thesis of Z. M. G. who received a scholarship from Coordination of Superior Level Staff Improvement (CAPES), Brazil. We thank Campinas State University (UNICAMP), São Paulo, Brazil, for insulin dosage; and São Lucas Laboratory Hospital, Parana, Brazil, for biochemical dosage.

This research received no specific grant from any funding agency, commercial or not-for-profit sectors.

Author contributions were: Z. M. G., A. C. V., B. K. A., V. M. C., P. H., D. W. d. S., T. A. d. S. - acquisition, analysis and interpretation of data. T. N. and H. R. d. O. E. - Western blotting and interpretation of data. S. G. - study design, data analysis and interpretation, article writing, critical review of relevant intellectual content. All authors approved the submitted version.

There were no conflicts of interest.

\section{References}

1. Schuch NJ, Garcia VC \& Martini LA (2009) Vitamina D e doenças endocrinometabólicas (Vitamin D and endocrinometabolic diseases). Arq Bras Endocrinol Metab 53, 625-633.

2. Norman AW (2008) From vitamin D to hormone D: fundamentals of the vitamin D endocrine system essential for good health. Am J Clin Nutr 88, 491S-499S.

3. Marcotorchino J, Tourniaire F, Astier J, et al. (2014) Vitamin D protects against diet-induced obesity by enhancing fatty acid oxidation. J Nutr Biochem 25, 1077-1083.

4. Percegoni N \& Castro JMA (2014) Vitamin D, overweight and obesity - a review. HU Rev 40, 209-219.

5. Zeitz U, Weber K, Soegiarto DW, et al. (2003) Impaired insulin secretory capacity in mice lacking a functional vitamin D receptor. FASEB J 17, 509-511.

6. Bourlon PM, Billaudel B \& Faure-Dussert A (2009) Influence of vitamin $\mathrm{D}_{3}$ deficiency and 1,25 dihydroxyvitamin $\mathrm{D}_{3}$ on de novo insulin biosynthesis in the islets of the rat endocrine pancreas. J Endocrinol 160, 87-95.

7. Jamka M, Wozniewicz M, Jeszkal J, et al. (2015) The effect of vitamin D supplementation on insulin and glucose metabolism in overweight and obese individuals: systematic review with meta-analysis. Sci Rep 5, 16142.

8. Kheder R, Hobbirk J, Saeed Z, et al. (2017) Vitamin $D_{3}$ supplementation of a high fat high sugar diet ameliorates prediabetic phenotype in female $\mathrm{LDLR}^{-/-}$and $\mathrm{LDLR}^{+/+}$mice. Immun Inflamm Dis 5, 151-162. 
9. Mathieu C, Gysemans C, Giulietti A, et al. (2005) Vitamin D and diabetes. Diabetologia 48, 1247-1257.

10. Wilcox G (2005) Insulin and insulin resistance. Clin Biochem Rev 26, 19-39.

11. Alejandro EU, Gregg B, Blandino-Rossano M, et al. (2015) Natural history of beta-cell adaptation and failure in type 2 diabetes. Mol Aspects Med 45, 19-42.

12. Palomer X, González-Clemente JM, Blanco-Vaca F, et al. (2008) Role of vitamin $\mathrm{D}$ in the pathogenesis of type 2 diabetes mellitus. Diabetes Obes Metab 10, 185-197.

13. Lahbib A, Ghodbane S, Louchami K, et al. (2015) Effects of vitamin $\mathrm{D}$ on insulin secretion and glucose transporter GLUT2 under static magnetic field in rat. Environ Sci Pollut Res In 22, 18011-18016.

14. Calle C, Maestro B \& García-Arencibia M (2008) Genomic actions of 1,25-dihydroxyvitamin $\mathrm{D}_{3}$ on insulin receptor gene expression, insulin receptor number and insulin activity in the kidney, liver and adipose tissue of streptozotocin-induced diabetic rats. BMC Mol Biol 9, 65.

15. Pittas AG, Harris SS, Stark PC, et al. (2007) The effects of calcium and vitamin D supplementation on blood glucose and markers of inflammation in non-diabetic adults. Diabetes Care 30, 980-986.

16. Pourshahidi LK (2015) Vitamin D and obesity: current perspectives and future directions. Proc Nutr Soc 74, 115-124.

17. de Boer I, Tinker LF, Connelly S, et al. (2008) Calcium plus vitamin $\mathrm{D}$ supplementation and the risk of incident diabetes mellitus in the Women's Health Initiative. Diabetes Care 31, 701-707.

18. Vangoitsenhoven R, Wolden-Kirk H, Lemaire KM, et al. (2016) Effect of a transcriptional inactive or absent vitamin $\mathrm{D}$ receptor on beta-cell function and glucose homeostasis in mice.J Jteroid Biochem Mol Biol 164, 309-317.

19. Neelankal JA \& Jiang FX (2018) An overview of type 2 diabetes and importance of vitamin $\mathrm{D}_{3}$-vitamin $\mathrm{D}$ receptor interaction in pancreatic $\beta$-cells. J Diabetes Complications 32, 429-443.

20. Gysemans CA, Cardozo AK, Callewaert H, et al. (2005) 1,25Dihydroxyvitamin $\mathrm{D}_{3}$ modulates expression of chemokines and cytokines in pancreatic islets: implications for prevention of diabetes in nonobese diabetic mice. Endocrinology 146, 1956-1964.

21. Gilon P \& Henquin JC (2017) Mechanisms and physiological significance of the cholinergic control of pancreatic beta-cell function. Nat Rev Endocrinol 22, 565-574.

22. Miranda RA, Agostinho AR, Trevenzoli IH, et al. (2014) Insulin oversecretion in MSG-obese rats is related to alterations in cholinergic muscarinic receptor subtypes in pancreatic islets. Cell Physiol Biochem 33, 1075-1086.

23. Kumar PT, Sherin A, Mohan SN, et al. (2011) Vitamin $\mathrm{D}_{3}$ restores altered cholinergic and insulin receptor expression in the cerebral cortex and muscarinic M3 receptor expression in pancreatic islets of streptozotocin induced diabetic rats. J Nutr Biochem 22, 418-425.

24. Olney JW (1969) Brain lesions, obesity and other disturbances in mice treated with monosodium glutamate. Science $\mathbf{1 6 4}$, 719-721.

25. Macho L, Fickova M, Jezova D, et al. (2000) Late effects of postnatal administration of monossodium gluatamate on insulin action in adult rats. Physiol Res 49, 79-85.

26. Diemen VV, Trindade EN \& Trindade MRM (2006) Experimental model to induce obesity in rats. Acta Cir Bras 21, 425-429.

27. Balbo SL, Gravena C, Bonfleur ML, et al. (2000) Insulin secretion and acetylcholinesterase activity in monosodium L-glutamate-induced obese mice. Horm Res 54, 186-191.

28. Lubaczeuski C, Balbo SL, Ribeiro RA, et al. (2015) Vagotomy ameliorates islet morphofunction and body metabolic homeostasis in MSG-obese rats. Braz I Med Biol Res 48, 447-457.

29. Leite NS, Ferreira TR, Rickli S, et al. (2013) Glycolytic and mitochondrial metabolism in pancreatic islets from MSG-treated obese rats subjected to swimming training. Cell Physiol Biochem 31, 242-256.

30. National Centre for the Replacement, Refinement \& Reduction of Animals in Research (2000) The ARRIVE Guidelines: Animal Research: Reporting of In Vivo Experiments. https://www.nc3rs. org.uk/sites/default/files/documents/Guidelines/ARRIVE\%20in\% 20portuguese\%20\%28Brazilian\%29.pdf (accessed May 2016).

31. Mattaraial VGM \& Moura ASAMT (2012) Productivity of Wistar rats in different mating systems. Ciênc Rural 42, 1490-1496.

32. Santos RE \& Vianna LM (2005) Effect of cholecalciferol supplementation on blood glucose in an experimental model of type 2 diabetes mellitus in spontaneously hypertensive rats and Wistar rats. Clin Chim Acta 358, 146-150.

33. Sadek KM \& Shaheen H (2014) Biochemical efficacy of vitamin $D$ in ameliorating endocrine and metabolic disorders in diabetic rats. Pharma Biol 52, 591-596.

34. Barella LF, de Oliveira JC, Branco RC, et al. (2012) Early exposure to a high-fat diet has more drastic consequences on metabolism compared with exposure during adulthood in rats. Horm Metab Res 44, 458-464.

35. Barella LF, Miranda RA, Franco CC, et al. (2014) Vagus nerve contributes to metabolic syndrome in high-fat diet-fed young and adult rats. Exp Physiol 100, 57-68.

36. Reeves PG, Nielsen FH \& Fahey GC (1993) AIN-93 purified diets for laboratory rodents: final report of the American Institute of Nutrition $A d H o c$ Writing Committee on the reformulation of the AIN-76A rodent diet. $J$ Nutr 123, 1939-1951

37. Bernardis LL \& Patterson BD (1968) Correlation between 'Lee index' and carcass fat content in weanling and adult female rats with hypothalamis lesions. J Endrocrinol 40, 527-528.

38. Rogers P \& Webb GP (1980) Estimation of body fat in normal and obese mice. Br J Nutr 43, 83-86.

39. Matthews DR, Hosker JP, Rudenski AS, et al. (1985) Homeostasis model assessment: insulin resistance and beta-cell function from fasting plasma glucose and insulin concentrations in man. Diabetologia 28, 412-419.

40. Antunes LC, Elkfury JL, Jornada MN, et al. (2016) Validation of HOMA-IR in a model of insulin-resistance induced by a high-fat diet in Wistar rats. Arch Endocrinol Metab 60, 138-143.

41. Lacy PE \& Kostianovsky M (1967) Method for the isolation of intact islets of Langerhans from the rat pancreas. Diabetes 16, 35-39.

42. Hara Y, Taniguchi H, Yamashiro Y, et al. (1988) An improved method for the isolation of islets from the rat pancreas. Exp Clin Endocrinol 91, 171-175.

43. Bradford MM (1976) A rapid and sensitive method for the quantitation microgram quantities of protein utilizing the principle of protein-dye binding. Anal Biochem $\mathbf{7 2}$, 248-254.

44. El-Fakhri N, McDevitta H, Shaikh MG, et al. (2014) Vitamin D and its effects on glucose homeostasis, cardiovascular function and immune function. Horm Res Paediatr 81, 363-378.

45. Blum M, Dolnikowski G, Seyoum E, et al. (2008) Vitamin $D_{3}$ in fat tissue. Endocrine 33, 90-94.

46. Kong J \& Li YC (2006) Molecular mechanism of 1,25-dihydroxyvitamin $\mathrm{D}_{3}$ inhibition of adipogenesis in 3T3-L1 cells. $A m \mathrm{~J}$ Physiol Endocrinol Metab 290, E916-E924.

47. Mahajan A \& Stahl CH (2009) Dihydroxy-cholecalciferol stimulates adipocytic differentiation of porcine mesenchymal stem cells. J Nutr Biochem 20, 512-520. 
48. Lira FS, Rosa JC, Cunha CA, et al. (2011) Supplementing $\alpha$-tocopherol (vitamin E) and vitamin $\mathrm{D}_{3}$ in high fat diet decrease IL- 6 production in murine epididymal adipose tissue and 3T3-L1 adipocytes following LPS stimulation. Lipids Health Dis 10, 37.

49. Jin W, Cuia B, Lia P, et al. (2018) 1,25-Dihydroxyvitamin $\mathrm{D}_{3}$ protects obese rats from metabolic syndrome via promoting regulatory T cell-mediated resolution of inflammation. Acta Pharma Sin 8, 178-187.

50. Nobre JL, Lisboa PC, Carvalho JC, et al. (2018) Leptin blocks the inhibitory effect of vitamin D on adipogenesis and cell proliferation in 3T3-L1 adipocytes. Gen Comp Endocrinol 266, 1-8.

51. Farhangi MA, Nameni $G$ \& Mesgari-Abbasi M (2017) Cardiac tissue oxidative stress and inflammation after vitamin D administrations in high fat- diet induced obese rats. Cadiovasc Disord 17, 161.

52. Wong KE, Szeto FL, Zhang W, et al. (2009) Involvement of the vitamin $\mathrm{D}$ receptor in energy metabolism: regulation of uncoupling proteins. Am J Physiol Endocrinol Metab 296, E820-E828.

53. Mitri J, Dawson-Hughes B, Hu FB, et al. (2011) Effects of vitamin $D$ and calcium supplementation on pancreatic beta cell function, insulin sensitivity, and glycemia in adults at high risk of diabetes: the Calcium and Vitamin D for Diabetes Mellitus (CaDDM) randomized controlled trial. Am J Clin Nutr 94, 486-494.

54. Olson ML, Maalouf NM, Oden JD, et al. (2012) Vitamin D deficiency in obese children and its relationship to glucose homeostasis. J Clin Endocrinol Metab 97, 279-285.

55. Jorde R, Fingenschau Y, Hutchinson M, et al. (2010) High serum 25-hydroxyvitamin D concentrations are associated with a favorable serum lipid profile. Eur J Clin Nutr 64, 1457-1464.

56. Sassi F, Tamone C \& D'Amelio P (2018) Vitamin D: nutrient, hormone, and immunomodulator. Nutrients 10, 1656.

57. Sadeghi K, Wessner B, Laggner U, et al. (2006) Vitamin $\mathrm{D}_{3}$ down-regulates monocyte TLR expression and triggers hyporesponsiveness to pathogen-associated molecular patterns. Eur J Immunol 36, 361-370.

58. Schneider LE, Schedl HP, McCain T, et al. (1977) Experimental diabetes reduces circulating 1,25-dihydroxyvitamin D in rat. Science 196, 1452-1452.

59. Scragg R, Holdaway I, Singh V, et al. (1995) Serum 25-hydroxyvitamin $\mathrm{D}_{3}$ levels decreased in impaired glucosetolerance and diabetes-mellitus. Diabetes Res Clin Pract 27, 181-188

60. Sollid ST, Hutchinson MYS, Fuskevag OM, et al. (2016) Large individual differences in serum 25-hydroxyvitamin D response to vitamin D supplementation: effects of genetic factors, body mass index, and baseline concentration. Results from a randomized controlled trial. Horm Metab Res 48, 27-34.

61. Nikooyeh B, Neyestani TR, Farvid M, et al. (2011) Daily consumption of vitamin D- or vitamin D + calcium-fortified yogurt drink improved glycemic control in patients with type 2 diabetes: a randomized clinical trial. Am J Clin Nutr 93, 764-771.

62. Forouhi NG, Luan IJ, Cooper A, et al. (2008) Baseline serum 25-hydroxy vitamin D is predictive of future glycemic status and insulin resistance the Medical Research Council Ely Prospective Study 1990-2000. Diabetes 57, 2619-2665.

63. Parisi E, Bozic M, Ibarz M, et al. (2010) Sustained activation of renal N-methyl-D-aspartate receptors decreases vitamin D synthesis: a possible role for glutamate on the onset of secondary HPT. Am J Physiol Endocrinol Metab 299, E825-E831.

64. Dou D, Yang B, Gan H, et al. (2019) Vitamin D supplementation for the improvement of vascular function in patients with chronic kidney disease: a meta-analysis of randomized controlled trials. Int Urol Nephrol 51, 851-858.

65. Boušová I, Košt’áková Š, Matoušková P, et al. (2017) Monosodium glutamate induced-obesity changed the expression and activity of glutathione S-transferases in mouse heart and kidney. Pharmazie 72, 257-259. 